\title{
Dietary proline supplementation alters colonic luminal microbiota and bacterial metabolite composition between days 45 and 70 of pregnancy in Huanjiang mini-pigs
}

Yujiao $\mathrm{Ji}^{1 \dagger}$, Qiuping Guo ${ }^{1 \dagger}$, Yulong Yin ${ }^{1,2}$, Francois Blachier ${ }^{3}$ and Xiangfeng Kong ${ }^{1,2^{*}}$

\begin{abstract}
Background: Pregnancy is associated with important changes in gut microbiota composition. Dietary factors may affect the diversity, composition, and metabolic activity of the intestinal microbiota. Among amino acids, proline is known to play important roles in protein metabolism and structure, cell differentiation, conceptus growth and development, and gut microbiota re-equilibration in case of dysbiosis.

Results: Dietary supplementation with $1 \%$ proline decreased $(P<0.05)$ the amounts of Klebsiella pneumoniae, Peptostreptococcus productus, Pseudomonas, and Veillonella spp. in distal colonic contents than that in the control group. The colonic contents of Butyrivibrio fibrisolvens, Bifidobacterium sp., Clostridium coccoides, Clostridium coccoides-Eubacterium rectale, Clostridium leptum subgroup, Escherichia coli, Faecalibacterium prausnitzii, Fusobacterium prausnitzii, and Prevotella increased $(P<0.05)$ on $\mathrm{d} 70$ of pregnancy as compared with those on $\mathrm{d} 45$ of pregnancy. The colonic concentrations of acetate, total straight-chain fatty acid, and total short-chain fatty acids (SCFA) in the proline-supplemented group were lower $(P<0.05)$, and butyrate level $(P=0.06)$ decreased as compared with the control group. Almost all of the SCFA displayed higher $(P<0.05)$ concentrations in proximal colonic contents on $d 70$ of pregnancy than those on $d 45$ of pregnancy. The concentrations of 1,7-heptyl diamine $(P=0.09)$ and phenylethylamine $(P<0.05)$ in proximal colonic contents were higher, while those of spermidine $(P=0.05)$ and total bioamine $(P=0.06)$ tended to be lower in the proline-supplemented group than those in the control group. The concentrations of spermidine, spermine, and total bioamine in colonic contents were higher $(P<0.05)$ on $d 70$ of pregnancy than those measured on d 45 of pregnancy. In contrast, the concentration of phenylethylamine was lower $(P<0.05)$ on $d 70$ than on $d 45$ of pregnancy.

(Continued on next page)
\end{abstract}

\footnotetext{
* Correspondence: nnkxf@isa.ac.cn

${ }^{\dagger}$ Equal contributors

'National Engineering Laboratory for Pollution Control and Waste Utilization in Livestock and Poultry Production, Key Laboratory of Agro-ecological Processes in Subtropical Region, Institute of Subtropical Agriculture, Chinese Academy of Sciences, Changsha, Hunan 410125, China

${ }^{2}$ Research Center of Mini-pig, Huanjiang Observation and Research Station

for Karst Ecosysterms, Huanjiang, Guangxi 547100, China

Full list of author information is available at the end of the article
} 
(Continued from previous page)

Conclusion: These findings indicate that L-proline supplementation modifies both the colonic microbiota composition and the luminal concentrations of several bacterial metabolites. Furthermore, our data show that both the microbiota composition and the concentrations of bacterial metabolites are evolving in the course of pregnancy. These results are discussed in terms of possible implication in terms of luminal environment and consequences for gut physiology and health.

Keywords: Bacterial metabolites, Colonic microbiota, L-proline, Pregnant Huanjiang mini-pigs

\section{Background}

The gut microbiome of pigs is a robust ecosystem inhabited by about 100 trillion bacteria. The importance of the maintenance of host-microbiome symbiosis is underscored by the observation that dysbiotic shifts in microbiota are associated with inflammatory bowel disorders, type 2 diabetes, obesity, and pregnancy metabolic syndrome in humans [1-5]. The gut microbiota metabolizes dietary compounds in both the small and large intestines. The microbiota is present at low concentrations and the transit time is relatively rapid in the small intestine, while the concentration of bacteria is much higher and the transit time is much longer in the large intestine. The dietary compounds that are transferred from the small intestine to the large intestine are undigested or not fully digested compounds, notably undigested carbohydrates and proteins [6]. The metabolic activity of the microbiota allows for the synthesis of various compounds, including short-chain fatty acids (SCFA), indoles, ammonia, gaseous compounds, organic acids, bioamines, and vitamins. Among these various metabolites, some are considered beneficial whereas others are believed to exert deleterious effects on the intestinal mucosa, when present in excess [7]. For instance, among SCFA, butyrate is considered beneficial for the colonic mucosa, because it can exert some anti-inflammatory effects [8]. The SCFA can reach luminal concentrations of $130 \mathrm{mmol} / \mathrm{L}$ in the proximal colon [9]. The concentration of SCFA is related to the luminal $\mathrm{pH}$. As weak organic acids, SCFA can decrease the luminal $\mathrm{pH}$ and inhibit some pathogenic microorganisms, while increasing the absorption of some nutrients [10]. Bioamines are widely produced by various kinds of bacteria. Although limited amounts of bioamines have no detectable effect on health [11] and participate in the physiology of the host, larger quantities $(1.4 \mathrm{~g} / \mathrm{d})$ of bioamines can become harmful to humans and livestock [12].

Pregnancy is a biological process involving simultaneous changes in many physiological systems, including microbiome composition [13]. Many nutrients, especially amino acids (AA), are required to sustain a successful pregnancy. For instance, arginine is a conditionally essential AA involved by itself and/or through its metabolites, in spermatogenesis, embryonic survival, fetal growth, as well as maintenance of vascular tone and hemodynamics [14]. Some other amino acid concentrations must be tightly regulated to avoid deleterious effects in some fetal tissues. For instance, limited entry of dietary aspartate and glutamate into blood circulation is required to avoid brain injury in the fetuses [15]. Thus, several evidences indicate that AA play crucial roles in both female and male reproduction $[16,17]$.

Among AA, it has been shown that proline played several roles in the development of the placenta, conceptus, and fetus $[18,19]$. Increasing proline availability in maternal plasma in pigs enhances the concentrations of proline and polyamines in placentae and fetal fluids, and promotes fetal growth [19]. Faure et al. [20] found that dietary proline supply could promote mucin synthesis, re-equilibrate the gut microbiota, and favor mucosal healing in dextran sulfate sodium-treated rats. In addition, proline plays an important role in the metabolism and recycling of nitrogenous compounds in bacteria [10].

Gut microbiota changes markedly from the first to the third trimesters of pregnancy in human beings, with an overall increase in Proteobacteria and Actinobacteria, and reduced richness (i.e., lower species count). Interestingly, the mucosal surfaces of the gut during trimester 3 of pregnancy present low-grade inflammation [21]. Our previous study found that the colonic microbiota displayed spatial and temporal heterogeneity in composition, diversity, and species abundance in different colonic segments from the first to the third trimester of pregnancy [22]. Considering the effect of proline on several physiological functions during pregnancy, and the role of this amino acid as precursors of metabolites with biological effects; the present study was conducted to document the effects of $L$-proline on the colonic luminal microbiota and bacterial metabolite composition (including SCFA and bioamines) in Huanjiang mini-pigs, because pigs can be used as a relevant model for extrapolation to humans [23].

\section{Methods}

\section{Animals}

The present study was carried out in accordance with the Chinese guidelines for animal welfare and experimental protocols and was approved by the Animal Care and Use 
Committee of Institute of Subtropical Agriculture, Chinese Academy of Sciences [24]. A total of 32 primiparous Huanjiang mini-pigs [average initial body weight (BW) $28.30 \pm 0.87 \mathrm{~kg}$ ] were used in this study.

\section{Study design}

The gilts were obtained from a Huanjiang mini-pig farm located in Huanjiang County, Guangxi province, China. The experimental design consisted of a $2 \times 2$ factorial arrangement, with two dietary treatments: control (alanine) diet and experimental (proline) diet, and two pregnancy stages: $\mathrm{d} 45$ or 75 of pregnancy. The animals were randomly assigned to one of the two dietary groups on d 15 after mating, with eight pens per group and two sows per pen. The average BW of pigs in the control group and experimental group was $27.84 \pm 1.32 \mathrm{~kg}$ and $28.82 \pm 1.17 \mathrm{~kg}$, respectively. The animals received a same basal diet supplemented with $1 \% L$-proline or $0.77 \% L$-alanine in the control group. The basal diet was formulated to meet the nutrient requirements and physiological characteristics of Chinese local pigs (Table 1). All animals were housed in $2 \mathrm{~m} \times 3 \mathrm{~m}$ pens with cement flooring. Temperature in the room housing the pens was maintained at $22-28{ }^{\circ} \mathrm{C}$. All the pigs had access to drinking water ad libitum from a nipple drinker and were fed twice daily (at 08:30 and 16:30 h) with their diets (approximately 3.0\% of BW) from a feeder.

\section{Sample collection}

On d 45 or 70 of pregnancy, eight sows per group were weighed and sacrificed using general anesthesia for sample collection at $12 \mathrm{~h}$ after the last feeding $[25,26]$. After colon recovery, luminal contents of the proximal colon $(10 \mathrm{~cm}$ at posterior to the ileocecal valve) and the distal

Table 1 Composition and nutrient levels of the basal diet (air-dry basis, \%)

\begin{tabular}{|c|c|c|c|}
\hline Ingredients & Content & Nutrient & Levels $^{\mathrm{b}}, \%$ \\
\hline Corn & 54.00 & Digestive energy, MJ/kg & 13.40 \\
\hline Soybean meal & 12.00 & Crude protein & 12.04 \\
\hline Rice bran & 30.00 & Calcium & 0.78 \\
\hline Premix ${ }^{a}$ & 4.00 & Phosphorus & 0.62 \\
\hline \multirow[t]{3}{*}{ Total } & 100.00 & Arginine & 0.65 \\
\hline & & Lysine & 0.53 \\
\hline & & Proline & 0.67 \\
\hline
\end{tabular}

${ }^{\mathrm{a}}$ One $\mathrm{kg}$ of premix contained the following: vitamin $\mathrm{A}, 10,200 \mathrm{IU}$; vitamin $\mathrm{D}_{3}$, $1600 \mathrm{IU}$; vitamin E, $75 \mathrm{IU}$; vitamin $\mathrm{K}_{3}, 75 \mathrm{mg}$; thiamine, $3 \mathrm{mg}$; riboflavin, $16 \mathrm{mg}$; pyridoxine, $3 \mathrm{mg}$; vitamin $\mathrm{B}_{12}, 0.8 \mathrm{mg}$; nicotinic acid, $69 \mathrm{mg}$; $D$-pantothenic acid, $42 \mathrm{mg}$; folic acid, $4 \mathrm{mg}$; biotin, $1 \mathrm{mg}$; chorine, $900 \mathrm{mg} ; \mathrm{Fe}\left(\mathrm{FeSO}_{4} \cdot \mathrm{H}_{2} \mathrm{O}\right)$, $150 \mathrm{mg} ; \mathrm{Cu}\left(\mathrm{CuSO}_{4} \cdot 5 \mathrm{H}_{2} \mathrm{O}\right), 11.2 \mathrm{mg} ; \mathrm{Zn}\left(\mathrm{ZnSO}_{4} \cdot \mathrm{H}_{2} \mathrm{O}\right), 63 \mathrm{mg} ; \mathrm{Mn}\left(\mathrm{MnSO}_{4} \cdot 5 \mathrm{H}_{2} \mathrm{O}\right)$, $32 \mathrm{mg}$; I (KI), $1.5 \mathrm{mg}$; $\mathrm{Co}\left(\mathrm{CoCO}_{3}\right), 0.3 \mathrm{mg}$; Se $\left(\mathrm{Na}_{2} \mathrm{SeO}_{3} \cdot \mathrm{H}_{2} \mathrm{O}\right), 0.25 \mathrm{mg} ; \mathrm{Ca}$ $\left(\mathrm{CaCO}_{3}\right), 200 \mathrm{mg}$; and $\mathrm{P}\left(\mathrm{KH}_{2} \mathrm{PO}_{4}\right), 20 \mathrm{mg}$

${ }^{\mathrm{b}}$ Digestive energy was a calculated value, while the others were measured values colon $(10 \mathrm{~cm}$ at the end of the colon) were collected and stored at $-80{ }^{\circ} \mathrm{C}$ for the extraction of total DNA of microbiota, as well as for determining the concentrations of SCFA and bioamines.

\section{Colonic microbiota composition analysis}

The total DNA was extracted from colonic contents using the QIAamp DNA Stool Mini kit (Qiagen, Hilden, Germany) after chemical and mechanical disruptions [27]. The quality and quantity of DNA were measured using a NanoDrop ND-1000 spectrophotometer (NanoDrop Technologies Inc., Wilmington, DE, USA). Quantitative real-time polymerase chain reaction (qPCR) was performed to determine the number of copies of the 16S rRNA genes of several targeted bacteria [28]. The primers, which were validated previously, are listed in Table 2. The qPCR was performed using SYBR Premix $E x \operatorname{Taq}^{\text {Tx }}$ II kit (TaKaRa Bio Inc., Shiga, Japan) on an ABI 7900HT Fast real-time PCR system (Applied Biosystems, Foster City, CA, USA). The standard curves for all determined bacteria were prepared using plasmid DNA containing each unique $16 \mathrm{~S}$ rRNA insert. The raw bacterial qPCR data were transformed to lg the number of target genomes per gram of wet digesta.

\section{Bacterial metabolite analysis}

The SCFA, including straight-chain fatty acids (acetate, propionate, butyrate, and pentanoate) and branchedchain fatty acids (BCFA; isobutyrate, and isopentanoate) were analyzed by gas chromatography as described by Zhou et al. [29]. The bioamines, including 1,7-heptyl diamine, cadaverine, phenylethylamine, putrescine, tryptamine, tyramine, spermidine, and spermine were analyzed by high-performance liquid chromatography as described by $\mathrm{Xu}$ et al. [30].

\section{Statistical analysis}

The data were analyzed by a mixed-effects model using SAS version 8.2 (SAS Institute Inc., Cary, NC, USA). Diet, pregnancy stage, and their interaction were included in the statistical model. Effects were considered statistically significant at $P<0.05$, while a tendency was considered for $0.05 \leq P<0.10$.

\section{Results \\ Microbiota composition}

Tables 3 and 4 summarized the effects of diets and pregnancy stages on microbiota composition of proximal and distal colonic contents, respectively, from pregnant Huanjiang mini-pigs. In proximal colonic contents, the proportion of Prevotella was lower $(P<0.05)$, but Firmicutes/Bacteroidetes $(\mathrm{F} / \mathrm{B})$ ratio was higher $(P<0.05)$ in the proline-supplemented group than in the control group. The proportions of Butyrivibrio fibrisolvens, 
Table 2 Primer pairs for 165 rRNA genes of bacteria

\begin{tabular}{|c|c|c|c|c|}
\hline Bacteria & Phylum & Primer sequences $\left(5^{\prime} \rightarrow 3^{\prime}\right)$ & Product size, bp & References \\
\hline Bacteroidetes & Bacteroidetes & $\begin{array}{l}\text { F: AGCAGCCGCGGTAAT } \\
\text { R: CTAHGCATTTCACCGCTA }\end{array}$ & 184 & {$[62]$} \\
\hline B. fibrisolvens & Firmicutes & $\begin{array}{l}\text { F: CGCATGATGCAGTGTGAAAAGCTC } \\
\text { R: CCTCCCGACACCTATTATTCATCG }\end{array}$ & 625 & [63] \\
\hline Bifidobacterium sp. & Actinobacteria & $\begin{array}{l}\text { F: CTCCTGGAAACGGGTGG } \\
\text { R: GGTGTTCTTCCCGATATCTACA }\end{array}$ & 226 & [64] \\
\hline C. coccoides & Firmicutes & $\begin{array}{l}\text { F: AAATGACGGTACCTGACTAA } \\
\text { R: CTITGAGTTCATTCTTGCGAA }\end{array}$ & 440 & {$[65]$} \\
\hline C. coccoides-E. rectale & Firmicutes & $\begin{array}{l}\text { F: CGGTACCTGACTAAGAAGC } \\
\text { R: AGTTTYATTCTTGCGAACG }\end{array}$ & 429 & {$[65]$} \\
\hline C. leptum subgroup & Firmicutes & $\begin{array}{l}\text { F: GCACAAGCAGTGGAGT } \\
\text { R: CTTCCTCCGTTTTGCAA }\end{array}$ & 239 & {$[66]$} \\
\hline E. coli & Proteobacteria & $\begin{array}{l}\text { F: GACCTCGGTTTAGTTCACAGA } \\
\text { R: CACACGCTGACGCTGACCA }\end{array}$ & 96 & {$[67]$} \\
\hline F. prausnitzii & Firmicutes & $\begin{array}{l}\text { F: AATTCCGCCTACCTCTGCACT } \\
\text { R: GGAGGAAGAAGGTCTTCGG }\end{array}$ & 248 & {$[68]$} \\
\hline Firmicutes & Firmicutes & $\begin{array}{l}\text { F: GTCAGCTCGTGTCGTGA } \\
\text { R: CCATTGTAKYACGTGTGT }\end{array}$ & 179 & [69] \\
\hline F. prausnitziib & Bacteroidetes & $\begin{array}{l}\text { F: CCCTTCAGTGCCGCAGT } \\
\text { R: GTCGCAGGATGTCAAGAC }\end{array}$ & 158 & {$[70]$} \\
\hline K. pneumoniae & Proteobacteria & $\begin{array}{l}\text { F: CCTGGATCTGACCCTGCAGTA } \\
\text { R: CCGTCGCCGTTCTGTTTC }\end{array}$ & 165 & [71] \\
\hline Lactobacillus sp. & Firmicutes & $\begin{array}{l}\text { F: TACATCCCAACTCCAGAACG } \\
\text { R: AAGCAACAGTACCACGACC }\end{array}$ & 116 & [72] \\
\hline M. elsdenii & Firmicutes & $\begin{array}{l}\text { F: GACCGAAACTGCGATGCTAGA } \\
\text { R: TCCAGAAAGCCGCTTTCGCCACT }\end{array}$ & 128 & [73] \\
\hline P. aeruginosa & Proteobacteria & $\begin{array}{l}\text { F: TCCAAGTTTAAGGTGGTAGGCTG } \\
\text { R: CTITCTTGGAAGCATGGCATC }\end{array}$ & 117 & [74] \\
\hline P. productus & Firmicutes & $\begin{array}{l}\text { F: AACTCCGGTGGTATCAGATG } \\
\text { R: GGGGCTTCTGAGTCAGGTA }\end{array}$ & 268 & {$[67]$} \\
\hline Pseudomonas & Proteobacteria & $\begin{array}{l}\text { F: GAGTTTGATCCTGGCTCAG } \\
\text { R: CCTTCCTCCCAACTT }\end{array}$ & 440 & [75] \\
\hline Prevotella & Bacteroidetes & $\begin{array}{l}\text { F: CACRGTAAACGATGGATGCC } \\
\text { R: GGTCGGGTTGCAGACC }\end{array}$ & 513 & {$[64]$} \\
\hline Roseburia & Firmicutes & $\begin{array}{l}\text { F: TACTGCATTGGAAACTGTCG } \\
\text { R: CGGCACCGAAGAGCAAT }\end{array}$ & 230 & [76] \\
\hline S. ruminantium & Firmicutes & $\begin{array}{l}\text { F: TGCTAATACCGAATGTTG } \\
\text { R: TCCTGCACTCAAGAAAGA }\end{array}$ & 513 & [77] \\
\hline Veillonella spp. & Firmicutes & $\begin{array}{l}\text { F: A(C/T)CAACCTGCCCTTCAGA } \\
\text { R: CGTCCCGATTAACAGAGCTT }\end{array}$ & 335 & [70] \\
\hline
\end{tabular}

\footnotetext{
${ }^{\mathrm{a}}$ Faecalibacterium prausnitzii
}

${ }^{\mathrm{b}}$ Fusobacterium prausnitzii

Bifidobacterium sp., Clostridium coccoides, Escherichia coli, Faecalibacterium prausnitzii, Fusobacterium prausnitzii, and Prevotella were higher $(P<0.05)$ on d 70 of pregnancy than on $\mathrm{d} 45$ of pregnancy. The proportion of Clostridium leptum subgroup $(P=0.09)$, Firmicutes $(P=0.07)$, Peptostreptococcus productus $(P=0.08)$, and $\mathrm{F} /$ $\mathrm{B}$ ratio $(P=0.07)$ displayed an increasing trend with pregnancy progress. The proportion of $C$. coccoidesEubacterium rectale and Firmicutes, and F/B ratio were changed $(P<0.05)$ owing to diet $\times$ stage interactions, and a trend was measured for Pseudomonas $(P=0.06)$.
In distal colonic contents, the proportion of Klebsiella pneumoniae $(P=0.06)$, $P$. productus $(P<0.05)$, Pseudomonas $(P=0.08)$, and Veillonella spp. $(P=0.09)$ tended to be lower in the proline-supplemented group than in the control group. The proportion of most bacteria, including B. fibrisolvens, Bifidobacterium sp., C. coccoides, C. coccoides-E. rectale, C. leptum subgroup, E. coli, Faecalibacterium prausnitzii, Firmicutes, Fusobacterium prausnitzii, $P$. productus, and Prevotella increased $(P<0.05)$, whereas that of Pseudomonas aeruginosa decreased $(P<0.05)$ with the progress of pregnancy. 
Table 3 Bacteria groups or species in proximal colonic contents of pregnant Huanjiang mini-pigs (lg bacteria cells/g wet weight)

\begin{tabular}{|c|c|c|c|c|c|c|c|c|}
\hline \multirow[t]{2}{*}{ Bacteria } & \multicolumn{2}{|c|}{ Control group } & \multicolumn{2}{|c|}{ Proline group } & \multirow[t]{2}{*}{ SEM } & \multicolumn{3}{|c|}{$P$-values } \\
\hline & $45 d$ & $70 \mathrm{~d}$ & $45 d$ & $70 \mathrm{~d}$ & & Diet & Day & Diet $\times$ Day \\
\hline Bacteroidetes & 11.18 & 11.21 & 10.96 & 11.06 & 0.23 & 0.18 & 0.63 & 0.78 \\
\hline B. fibrisolvens & 8.97 & 9.54 & 8.73 & 9.33 & 0.26 & 0.20 & 0.003 & 0.93 \\
\hline Bifidobacterium sp. & 8.97 & 9.98 & 8.73 & 9.98 & 0.24 & 0.71 & 0.001 & 0.70 \\
\hline C. coccoides & 10.23 & 10.77 & 10.01 & 10.76 & 0.25 & 0.47 & 0.001 & 0.54 \\
\hline C. coccoides-E. rectale & 9.94 & 10.31 & 9.68 & 10.09 & 0.24 & 0.11 & 0.90 & 0.01 \\
\hline C. leptum subgroup & 10.56 & 10.67 & 10.29 & 10.66 & 0.23 & 0.30 & 0.09 & 0.33 \\
\hline E. coli & 9.93 & 10.31 & 9.77 & 10.30 & 0.22 & 0.53 & 0.003 & 0.56 \\
\hline F. prausnitzii & 10.50 & 10.75 & 10.28 & 10.77 & 0.22 & 0.41 & 0.01 & 0.34 \\
\hline Firmicutes & 11.10 & 11.04 & 10.83 & 11.33 & 0.21 & 0.94 & 0.07 & 0.03 \\
\hline F. prausnitzii ${ }^{2}$ & 8.55 & 10.75 & 8.15 & 10.77 & 0.29 & 0.41 & 0.01 & 0.34 \\
\hline K. pneumoniae & 7.57 & 7.53 & 7.72 & 7.51 & 0.24 & 0.67 & 0.39 & 0.56 \\
\hline Lactobacillus sp. & 10.27 & 10.53 & 10.25 & 10.61 & 0.31 & 0.90 & 0.22 & 0.84 \\
\hline M. elsdenii & 8.23 & 7.55 & 7.72 & 7.88 & 0.33 & 0.75 & 0.36 & 0.14 \\
\hline P. aeruginosa & 8.73 & 8.43 & 8.93 & 8.72 & 0.25 & 0.15 & 0.13 & 0.76 \\
\hline P. productus & 7.87 & 8.07 & 7.81 & 8.04 & 0.22 & 0.68 & 0.08 & 0.87 \\
\hline Pseudomonas & 6.80 & 7.24 & 7.03 & 6.99 & 0.22 & 0.92 & 0.12 & 0.06 \\
\hline Prevotella & 9.01 & 9.86 & 8.59 & 9.23 & 0.30 & 0.03 & 0.004 & 0.67 \\
\hline Roseburia & 8.31 & 8.47 & 7.95 & 8.37 & 0.28 & 0.27 & 0.16 & 0.54 \\
\hline S. ruminantium & 7.26 & 7.53 & 7.03 & 7.17 & 0.28 & 0.16 & 0.34 & 0.74 \\
\hline Veillonella spp. & 7.21 & 6.83 & 6.88 & 6.90 & 0.27 & 0.48 & 0.34 & 0.29 \\
\hline F/B ratio & 0.99 & 0.99 & 0.99 & 1.02 & 0.05 & 0.02 & 0.07 & 0.01 \\
\hline
\end{tabular}

F/B ratio Firmicutes/Bacteroidetes ratio

The F/B ratio displayed an increasing trend $(P=0.09)$ with the progress of pregnancy. The proportion of Bifidobacterium sp. $(P=0.09), K$. pneumoniae $(P<0.09)$, $P$. aeruginosa $(P=0.06), P$. productus $(P=0.06)$, and Pseudomonas $(P=0.07)$ changed owing to the diet $\times$ stage interactions.

\section{The SCFA concentrations}

The SCFA concentrations in colonic contents of pregnant Huanjiang mini-pigs are summarized in Table 5. In proximal colonic contents, the concentrations of acetate, total straight-chain fatty acids, and total SCFA were lower $(P<0.05)$ in the proline-supplemented group. The concentrations of butyrate tended to be decreased $(P=0.06)$ in the proline-supplemented group, when compared with the control group. Almost all of the SCFA in proximal colonic contents presented higher $(P<0.05)$ concentrations on $\mathrm{d} 70$ of pregnancy than on $\mathrm{d} 45$ of pregnancy. The concentrations of acetate $(P=0.099)$, butyrate $(P=0.05)$, isovalerate $(P=0.09)$, total straight-chain fatty acids $(P=0.06)$, and total SCFA $(P=0.05)$ were changed, or tended to be changed, owing to the diet $\times$ stage interactions. In distal colonic contents, the concentrations of isobutyrate and total BCFA were higher $(P<0.05)$ on $\mathrm{d} 70$ of pregnancy than on $\mathrm{d} 45$ of pregnancy. Proline supplementation, however, did not affect the concentrations of SCFA.

\section{Bioamine contents}

The bioamine concentrations in colonic contents of pregnant Huanjiang mini-pigs are summarized in Table 6. In proximal colonic contents, the concentrations of 1,7-heptyl diamine $(P=0.09)$ and phenylethylamine $(P<0.05)$ tended to and were significantly higher in the proline-supplemented group, respectively, whereas those of spermidine $(P=0.05)$ and total bioamine $(P=0.06)$ were lower or tended to be lower than those in the control group. The concentrations of spermidine, spermine, and total bioamine were higher $(P<0.05)$ on $\mathrm{d} 70$ of pregnancy, whereas that of phenylethylamine $(P<0.05)$ was lower than those on $d 45$ of pregnancy. The concentrations of 1,7-heptyl diamine, phenylethylamine, spermine, and tryptamine displayed differences $(P<0.05)$ according to diet $\times$ stage interactions, as well as total bioamine concentration $(P=0.096)$. In distal colonic contents, the concentrations of 1,7-heptyl diamine $(P=0.07)$ and tryptamine $(P<0.05)$ were higher in the proline-supplemented group, whereas those of cadaverine 
Table 4 Bacteria groups or species in distal colonic contents of pregnant Huanjiang mini-pigs (lg bacteria cells/g wet weight)

\begin{tabular}{|c|c|c|c|c|c|c|c|c|}
\hline \multirow[t]{2}{*}{ Item } & \multicolumn{2}{|c|}{ Control group } & \multicolumn{2}{|c|}{ Proline group } & \multirow[t]{2}{*}{ SEM } & \multicolumn{3}{|c|}{$P$-values } \\
\hline & $45 d$ & $70 \mathrm{~d}$ & $45 d$ & $70 \mathrm{~d}$ & & Diet & Day & Diet $\times$ Day \\
\hline Bacteroidetes & 11.04 & 11.03 & 10.91 & 11.11 & 0.23 & 0.84 & 0.47 & 0.46 \\
\hline B. fibrisolvens & 8.72 & 9.12 & 8.63 & 9.22 & 0.23 & 0.98 & 0.001 & 0.49 \\
\hline Bifidobacterium sp. & 9.17 & 9.99 & 9.39 & 9.53 & 0.27 & 0.52 & 0.02 & 0.08 \\
\hline C. coccoides & 10.28 & 10.72 & 10.19 & 10.61 & 0.21 & 0.40 & 0.001 & 0.94 \\
\hline C. coccoides-E. rectale & 9.79 & 10.12 & 9.81 & 10.08 & 0.23 & 0.95 & 0.04 & 0.84 \\
\hline C. leptum subgroup & 9.98 & 10.42 & 9.97 & 10.19 & 0.24 & 0.42 & 0.04 & 0.44 \\
\hline E. coli & 9.89 & 10.14 & 9.82 & 10.21 & 0.22 & 0.98 & 0.02 & 0.59 \\
\hline F. prausnitzii ${ }^{1}$ & 10.10 & 10.33 & 10.11 & 10.35 & 0.20 & 0.88 & 0.03 & 0.94 \\
\hline Firmicutes & 10.77 & 11.08 & 10.70 & 10.95 & 0.21 & 0.38 & 0.02 & 0.78 \\
\hline F. prausnitzii ${ }^{2}$ & 7.92 & 8.43 & 7.91 & 8.29 & 0.23 & 0.57 & 0.003 & 0.65 \\
\hline K. pneumoniae & 7.66 & 7.39 & 7.15 & 7.43 & 0.22 & 0.06 & 0.98 & 0.03 \\
\hline Lactobacillus sp. & 9.82 & 10.10 & 9.73 & 9.97 & 0.31 & 0.66 & 0.29 & 0.93 \\
\hline M. elsdenii & 8.12 & 7.77 & 7.84 & 7.84 & 0.31 & 0.68 & 0.48 & 0.49 \\
\hline P. aeruginosa & 8.70 & 8.68 & 9.13 & 8.52 & 0.24 & 0.37 & 0.04 & 0.06 \\
\hline P. productus & 7.70 & 8.23 & 7.65 & 7.77 & 0.20 & 0.02 & 0.01 & 0.06 \\
\hline Pseudomonas & 7.23 & 6.81 & 6.60 & 6.82 & 0.26 & 0.08 & 0.56 & 0.07 \\
\hline Prevotella & 8.61 & 9.25 & 8.18 & 8.90 & 0.31 & 0.12 & 0.01 & 0.87 \\
\hline Roseburia & 7.98 & 8.07 & 8.06 & 8.12 & 0.28 & 0.75 & 0.69 & 0.93 \\
\hline S. ruminantium & 7.03 & 7.12 & 7.01 & 7.37 & 0.29 & 0.61 & 0.31 & 0.54 \\
\hline Veillonella spp. & 7.19 & 6.98 & 6.83 & 6.78 & 0.25 & 0.09 & 0.43 & 0.63 \\
\hline F/B ratio & 0.98 & 1.00 & 0.98 & 0.99 & 0.06 & 0.46 & 0.09 & 0.21 \\
\hline
\end{tabular}

F/B ratio Firmicutes/Bacteroidetes ratio

$(P<0.05)$, phenylethylamine $(P<0.05)$, and tyramine $(P=0.098)$ were lower than those in the control group. The concentrations of spermidine $(P<0.05)$, spermine $(P<0.05)$, tryptamine $(P<0.05)$, and total bioamine $(P=0.08)$ were higher, but cadaverine and phenylethylamine were lower $(P<0.05)$ on $d 70$ than on d 45 of pregnancy. The concentrations of cadaverine, phenylethylamine, putrescine, and tryptamine displayed differences $(P<0.05)$ according to diet $\times$ stage interactions.

\section{Discussion}

Several studies revealed that the indigenous microbiota in the gut play important roles in the metabolism and recycling of nitrogenous compounds, including AA [10, 20]. Furthermore, changes in gut microbiota of pregnant human and animals have been documented in recent years $[13,23,31]$. The present study indicates that dietary supplementation with proline affects the colonic luminal microbiota and bacterial metabolite composition in Huanjiang mini-pigs. In addition, our study confirms that the composition of bacteria in the colon, as well as the luminal environment, differ according to the stage of pregnancy.
Pregnancy is a time of dramatic host remodeling for the mother, and may be partly viewed as the development of adaptive processes in a context of major new physiological constraints. Our previous study showed that during pregnancy, both the body weight and fat over lean mass ratio increased in the Huanjiang minipigs [32]. In agreement with the above, it has been reported that pregnant female Ossabaw mini-pigs displayed higher body weight, notably due to fat deposition [33], which was association with higher levels of triglyceride and very low-density lipoprotein [34], and lower levels of high-density lipoprotein cholesterol, and lowdensity lipoprotein cholesterol [35].

A previous study showed that the pregnancy stage and diet composition may affect gut microbial composition [36]. The present study confirms these results and elucidates that the proportion of Prevotella increased with progress of pregnancy. This is consistent with the study of Collado and Isolauri [3], who reported that the abundances of Bacteroides-Prevotella group, Clostridium, and Staphylococcus increased from first trimester to third trimester of normal-weight and overweight pregnant women. Moreover, Santacruz et al. [37] confirmed that the proportion of Firmicutes, especially Clostridium 
Table 5 Short-chain fatty acid concentrations in colonic contents of pregnant Huanjiang mini-pigs $(\mathrm{mg} / \mathrm{g})$

\begin{tabular}{|c|c|c|c|c|c|c|c|c|}
\hline \multirow[t]{2}{*}{ Item } & \multicolumn{2}{|c|}{ Control group } & \multicolumn{2}{|c|}{ Proline group } & \multirow[t]{2}{*}{ SEM } & \multicolumn{3}{|c|}{$P$-values } \\
\hline & $45 d$ & $70 \mathrm{~d}$ & $45 d$ & $70 \mathrm{~d}$ & & Diet & Day & Diet $\times$ Day \\
\hline \multicolumn{9}{|l|}{ Proximal colonic contents } \\
\hline Acetate & 16.72 & 34.24 & 14.70 & 22.76 & 1.07 & 0.02 & $<0.01$ & 0.099 \\
\hline Propionate & 5.95 & 12.56 & 6.36 & 9.44 & 0.71 & 0.28 & $<0.01$ & 0.16 \\
\hline Isobutyrate & 0.23 & 0.92 & 0.28 & 0.71 & 0.19 & 0.41 & $<0.01$ & 0.17 \\
\hline Butyrate & 3.64 & 6.69 & 3.68 & 4.18 & 0.51 & 0.06 & 0.010 & 0.05 \\
\hline Isovalerate & 0.19 & 0.70 & 0.21 & 0.50 & 0.16 & 0.15 & $<0.01$ & 0.09 \\
\hline Valerate & 0.43 & 1.43 & 0.44 & 1.16 & 0.24 & 0.35 & $<0.01$ & 0.34 \\
\hline Total BCFA & 0.42 & 1.61 & 0.49 & 1.21 & 0.25 & 0.28 & $<0.01$ & 0.13 \\
\hline Total straight-chain fatty acids & 26.75 & 54.92 & 25.18 & 37.54 & 1.27 & 0.02 & $<0.01$ & 0.06 \\
\hline Total SCFA & 27.17 & 56.53 & 25.67 & 38.74 & 1.29 & 0.03 & $<0.01$ & 0.05 \\
\hline \multicolumn{9}{|l|}{ Distal colonic contents } \\
\hline Acetate & 10.48 & 9.07 & 10.38 & 10.02 & 0.60 & 0.60 & 0.28 & 0.52 \\
\hline Propionate & 4.01 & 3.81 & 4.00 & 4.60 & 0.38 & 0.24 & 0.54 & 0.24 \\
\hline Isobutyrate & 0.36 & 0.49 & 0.34 & 0.48 & 0.13 & 0.78 & 0.01 & 0.92 \\
\hline Butyrate & 2.94 & 2.95 & 2.93 & 2.71 & 0.38 & 0.71 & 0.75 & 0.73 \\
\hline Isovalerate & 0.33 & 0.39 & 0.31 & 0.34 & 0.13 & 0.34 & 0.25 & 0.62 \\
\hline Valerate & 0.48 & 0.50 & 0.41 & 0.51 & 0.14 & 0.57 & 0.17 & 0.39 \\
\hline Total BCFA & 0.69 & 0.88 & 0.66 & 0.82 & 0.18 & 0.53 & 0.03 & 0.84 \\
\hline Total straight-chain fatty acids & 17.90 & 16.33 & 17.72 & 17.85 & 0.76 & 0.61 & 0.59 & 0.52 \\
\hline Total SCFA & 18.59 & 17.21 & 18.38 & 18.67 & 0.77 & 0.64 & 0.69 & 0.54 \\
\hline
\end{tabular}

clusters, is associated with excessive BW and obesity in human subjects. Similar to the obese human subjects, the sows at $\mathrm{d} 70$ of pregnancy had increased proportions of C. coccoides, C. leptum subgroup, E. coli, Faecalibacterium prausnitzii, P. productus, and Firmicutes, as compared with those at d 45 of pregnancy. The increased proportion of Firmicutes is considered to affect the metabolic potential of the gut microbiota and enhance the capacity of the body to harvest energy from the diet [38]. In addition, colonization of germ-free mice with the butyrate-producing bacteria $B$. fibrisolvens rescued colonic epithelia from the energy starvation status [39]. Based on our results, it appeared that some bacteria involved in indigestible carbohydrate fermentation increased by $d 70$ of pregnancy, thereby allowing the production of more SCFA and increased energy recycling for the pregnant sows and their fetuses.

Bacterial cross-feeding has a huge impact on the final balance of the SCFA production, absorption, and efficient exploitation of the substrates in the gut [40]. The vast majority of acetate in the body is produced by the gut microbiota, and the total fecal propionate concentration is linked to the relative abundance of Bacteroidetes and Firmicutes [41]. Butyrate produced by the gut microbiota is dependent on butyrate-producers, such as Faecalibacterium, Eubacterium, and Roseburia [42]. In accordance with some data on the evolution of the microbiota composition during pregnancy, SCFA presented higher concentrations in proximal colonic contents. In the distal colonic contents recovered at d 70 of pregnancy. Isobutyrate and total BCFA concentrations in the distal colonic contents were higher at $\mathrm{d} 70$ than at $\mathrm{d}$ 45 of pregnancy. As BCFA concentrations are considered as indicators of protein catabolism by the microbiota in the luminal intestinal content [43], these results are suggestive of increased protein fermentation in the distal colon at $\mathrm{d} 70$ of pregnancy as compared with that at $\mathrm{d} 45$. The present study shows that the proportion of saccharolytic bacteria generating SCFA [44], including $C$. coccoides, C. coccoides-E. rectale, and C. leptum subgroups, increases similarly when compared with the Firmicutes phylum. Faecalibacterium prausnitzii, Fusobacterium, and Clostridium are known butyrate producers [45-48]. Prevotella had been proposed to enhance calorie extraction from resistant starches, oligosaccharides, and other indigested carbohydrates [49], and its concentration is associated with increased colonic SCFA. In addition to participating in the digestive process, microbiota allows local synthesis of SCFA, which are used as energy substrates by the host [50]. Parts of SCFA are absorbed and metabolized by the colonocytes, while the unmetabolized portion can enter 
Table 6 Bioamine concentrations in colonic contents of pregnant Huanjiang mini-pigs $(\mu \mathrm{g} / \mathrm{g})$

\begin{tabular}{|c|c|c|c|c|c|c|c|c|}
\hline \multirow[t]{2}{*}{ Items } & \multicolumn{2}{|c|}{ Control group } & \multicolumn{2}{|c|}{ Proline group } & \multirow[t]{2}{*}{ SEM } & \multicolumn{3}{|c|}{$P$-values } \\
\hline & $45 d$ & $70 d$ & $45 d$ & $70 \mathrm{~d}$ & & Diet & Day & Diet $\times$ Day \\
\hline \multicolumn{9}{|c|}{ Proximal colonic contents } \\
\hline 1,7-heptyl diamine & 2.22 & 2.36 & 2.95 & 2.28 & 0.26 & 0.09 & 0.15 & 0.04 \\
\hline Cadaverine & 13.61 & 12.77 & 12.99 & 16.67 & 0.98 & 0.50 & 0.56 & 0.36 \\
\hline Phenylethylamine & 6.67 & 8.64 & 12.99 & 6.36 & 0.44 & 0.001 & $<0.01$ & $<0.01$ \\
\hline Putrescine & 20.30 & 24.38 & 21.83 & 19.12 & 0.99 & 0.45 & 0.78 & 0.18 \\
\hline Spermidine & 35.97 & 67.63 & 30.96 & 44.35 & 1.64 & 0.05 & 0.005 & 0.19 \\
\hline Spermine & 5.71 & 15.79 & 9.15 & 10.67 & 0.83 & 0.64 & 0.006 & 0.03 \\
\hline Tryptamine & 1.46 & 2.14 & 2.46 & 1.03 & 0.39 & 0.89 & 0.35 & 0.02 \\
\hline Tyramine & 2.82 & 2.53 & 2.02 & 1.79 & 0.45 & 0.15 & 0.61 & 0.96 \\
\hline Total bioamine & 101.90 & 151.18 & 98.32 & 106.42 & 2.15 & 0.06 & 0.03 & 0.096 \\
\hline \multicolumn{9}{|l|}{ Distal colonic contents } \\
\hline 1,7-heptyl diamine & 1.63 & 1.24 & 1.80 & 2.06 & 0.32 & 0.07 & 0.78 & 0.22 \\
\hline Cadaverine & 15.81 & 6.23 & 5.71 & 6.81 & 0.80 & 0.01 & 0.02 & 0.005 \\
\hline Phenylethylamine & 10.09 & 4.47 & 5.70 & 4.57 & 0.54 & 0.011 & $<0.01$ & 0.008 \\
\hline Putrescine & 13.87 & 10.51 & 8.84 & 14.30 & 0.65 & 0.56 & 0.33 & 0.001 \\
\hline Spermidine & 29.54 & 33.79 & 22.67 & 38.67 & 1.21 & 0.79 & 0.02 & 0.13 \\
\hline Spermine & 7.31 & 9.92 & 7.86 & 9.95 & 0.66 & 0.79 & 0.046 & 0.81 \\
\hline Tryptamine & 0.28 & 0.23 & 0.17 & 1.31 & 0.23 & 0.002 & 0.001 & $<0.01$ \\
\hline Tyramine & 1.71 & 1.87 & 0.96 & 1.67 & 0.33 & 0.098 & 0.12 & 0.32 \\
\hline Total bioamine & 64.82 & 73.97 & 68.31 & 79.33 & 1.47 & 0.42 & 0.08 & 0.86 \\
\hline
\end{tabular}

diverse carbohydrates and lipid metabolic routes in the peripheral tissues. While most of the butyrate produced by the microbiota is metabolized in enterocytes/ colonocytes during its transfer from the intestinal lumen to the bloodstream, propionate mainly incorporates into the gluconeogenesis pathway, while acetate is mostly metabolized into the lipid biosynthesis pathway [41]. Collectively, the increased SCFA production and absorption may provide additional nutrients for pregnant sows; however, additional work outside of the scope of the present study is necessary to test this hypothesis.

The AA serve not only as protein building bricks but also act as energy substrates, signaling molecules, and/or as precursors for bioactive compounds [51]. Thus, AA intervene in the regulation of diverse physiological process related to the reproductive functions, ranging from spermatogenesis to oocyte fertilization and embryo implantation [52]. In the large intestine, AA are not absorbed to any significant extent by the colonic mucosa (except in the neonatal period), and thus are mostly metabolized by the microbiota into various intermediary and end products [53]. The present study showed that dietary proline supplementation decreased the proportion of Prevotella in the proximal colonic contents, and the proportions of $K$. pneumoniae and P. productus in the distal colonic contents. These bacterial species can metabolize carbohydrates, especially indigestible fiber [54]. Klebsiella pneumoniae, which is the most significant member of Enterobacteriaceae and Peptostreptococcus productus, are predominant for the utilization of glutamate or tryptophan [52]. Ren et al. [55] reported that dietary proline supplementation confers a positive immune effect in porcine circovirus-infected pregnant and non-pregnant mice.

Proteins are degraded by the bacterial protease and peptidase activities, and the AA released from the proteins can be precursors of various bioamines in the colon via specific AA decarboxylation pathways by specific bacteria [56]. In bacteria, the bioamines are involved in many processes related to transcription, translation, growth, metabolism, and other functions, including improved acid resistance, protection from oxidative stress and host immunological defenses [56-60]. For instance, E. coli synthesized cadaverine during anaerobic growth at low $\mathrm{pH}$ in the presence of its precursor lysine [61]. Several bioamine-producing taxa belong to Prevotella and Megasphaera [60]. This may explain why the concentrations of spermidine, spermine, and total bioamines in colonic contents increased with the progress of pregnancy.

The way by which supplemental proline exerts its effect on colonic microbiota remains elusive, considering 
that the capacity of the small intestine for the absorption of amino acids is high. In other words, the dietary proline originating from the dietary proteins and supplement is most likely large, if not totally absorbed by the small intestinal epithelium. Thus, we propose that the effects of dietary proline on the colonic ecosystem would be dependent, at least in part, on the effect of this AA on the microbiota composition and metabolic activity in the small intestine; such effects presumably affect the large intestinal luminal environment. This hypothesis is worthy of testing in future experiments.

\section{Conclusion}

In conclusion, the present study indicates that $L$-proline supplementation modifies the colonic microbiota composition and the luminal concentrations of several bacterial metabolites. Furthermore, our data show that both the microbiota composition and the concentrations of bacterial metabolites are evolving in the course of pregnancy. The changes in the luminal environment associated with these changes in microbiota composition need to be evaluated in terms of beneficial over deleterious effects for the colonic mucosa and for peripheral tissues in the mother and the fetuses.

\section{Abbreviations}

AA: Amino acids; BCFA: Branched-chain fatty acids; qPCR: Quantitative realtime polymerase chain reaction; SCFA: Short-chain fatty acids

\section{Acknowledgments}

We thank staffs and postgraduate students of Hunan Provincial Engineering Research Center of Healthy Livestock for collecting samples and technicians from key laboratory of agro-ecological processes in subtropical region for providing technical assistance. We also thank Editage [http://online.editage.cn/] for English language editing.

\section{Funding}

The present work was jointly supported by grants from the National Nature Science Foundation of China (31572421 and 31270044), National Key R \& D Program (2017YFD0500503), "Western Light" key program for Talent Cultivation from Chinese Academy of Sciences, and Chinese Academy of Sciences Visiting Professorship for Senior International Scientists (F. Blachier, 2013T2S0014).

\section{Availability of data and materials}

The datasets supporting the conclusions of this article are included within the article.

\section{Authors' contributions}

XFK designed the study; YJJ, QPG, and XFK carried out the experiments and data analysis; YJJ, XFK, YLY, and FB drafted and revised the manuscript. All authors have read and approved the final version of the manuscript.

\section{Ethics approval and consent to participate}

This article does not contain any studies with human participants performed by any of the authors. The use of animals for this research was approved by the Institutional Animal Care and Use Committee of the Institute of Subtropical Agriculture, Chinese Academy of Sciences. All procedures performed in studies involving animals were in accordance with the ethical standards of the institution or practice at which the studies were conducted.

\section{Consent for publication}

Not applicable.

\section{Competing interests}

The authors declare that they have no competing interests.

\section{Author details}

${ }^{1}$ National Engineering Laboratory for Pollution Control and Waste Utilization in Livestock and Poultry Production, Key Laboratory of Agro-ecological Processes in Subtropical Region, Institute of Subtropical Agriculture, Chinese Academy of Sciences, Changsha, Hunan 410125, China. ${ }^{2}$ Research Center of Mini-pig, Huanjiang Observation and Research Station for Karst Ecosysterms, Huanjiang, Guangxi 547100, China. ${ }^{3}$ UMR 914 INRA/AgroParisTech/Universite Paris-Sacaly, Nutrition Physiology and Ingestive Behavior, 75005 Paris, France.

Received: 20 April 2017 Accepted: 10 January 2018

Published online: 30 January 2018

\section{References}

1. Turnbaugh PJ, Hamady M, Yatsunenko T, Cantarel BL, Duncan A, Ley $R E$, et al. A core gut microbiome in obese and lean twins. Nature. 2009;457(7228):480-7.

2. Karlsson FH, Tremaroli V, Nookaew I, Bergstrom G, Behre CJ, Fagerberg B, et al. Gut metagenome in European women with normal, impaired and diabetic glucose control. Nature. 2013;498(7452):99-103.

3. Collado MC, Isolauri E, Laitinen K, Salminen S. Distinct composition of gut microbiota during pregnancy in overweight and normal-weight women. Am J Clin Nutr. 2008;88(4):894-9.

4. Feng ZM, Li TJ, Wu L, Xiao DF, Blachier F, Yin YL. Monosodium L-glutamate and dietary fat differently modify the composition of the intestinal microbiota in growing pigs. Obes Facts. 2015;8(2):87-100.

5. Weitkunat K, Schumann S, Petzke KJ, Blaut M, Loh G, Klaus S. Effects of dietary inulin on bacterial growth, short-chain fatty acid production and hepatic lipid metabolism in gnotobiotic mice. J Nutr Biochem. 2015;26(9):929-37.

6. Portune KJ, Beaumont M, Davila AM, Tomé D, Blachier F, Sanz Y. Gut microbiota role in dietary protein metabolism and health-related outcomes: the two sides of the coin. Trends Food Sci Tech. 2016;57:213-32.

7. Blachier F, Beaumont M, Andriamihaja M, Davila AM, Lan A, Grauso M, et al. Changes in the luminal environment of the colonic epithelial cells and physiopathological consequences. Am J Pathol. 2017;187(3):476-86.

8. Thibault R, Blachier F, Darcy-Vrillon B, de Coppet P, Bourreille A, Segain P. Butyrate utilization by the colonic mucosa in inflammatory bowel diseases: a transport deficiency. Inflamm Bowel Dis. 2017;16(4):684-95.

9. Hamer HM, Jonkers D, Venema K, Vanhoutvin S, Troost FJ, Brummer RJ. Review article: the role of butyrate on colonic function. Aliment Pharmacol Ther. 2008;27(2):104-19.

10. Macfarlane GT, Macfarlane S. Bacteria, colonic fermentation, and gastrointestinal health. J AOAC Int. 2012;95(1):50-60.

11. Bardocz S, Duguid TJ, Brown DS, Grant G, Pusztai A, White A, et al. The importance of dietary polyamines in cell regeneration and growth. $\mathrm{Br} J$ Nutr. 1995;73(6):819-28.

12. Fusi E, Rossi L, Rebucci R, Cheli F, Di Giancamillo A, Domeneghini C, et al. Administration of biogenic amines to Saanen kids: effects on growth performance, meat quality and gut histology. Small Ruminant Res. 2004;53(1-2):1-7.

13. Nuriel-Ohayon $M$, Neuman $H$, Koren O. Microbial changes during pregnancy, birth, and infancy. Front Microbiol. 2016;(1031). https://doi.org/ 10.3389/fmicb.2016.01031. eCollection 2016

14. Bazer FW. Contributions of an animal scientist to understanding the biology of the uterus and pregnancy. Reprod Fertil Dev. 2013;25(1):129-47.

15. Wu GY, Bazer FW, Davis TA, Kim SW, Li P, Rhoads JM, et al. Arginine metabolism and nutrition in growth, health and disease. Amino Acids. 2009:37:153-68.

16. Wu GY, Bazer FW, Johnson GA, Herring C, Seo H, Dai ZL, et al. Functional amino acids in the development of the pig placenta. Mol Reprod Dev. 2017;84(9):870-82.

17. Wu GY, Bazer FW, Satterfield MC, Li XL, Wang XQ, Johnson GA, et al. Impacts of arginine nutrition on embryonic and fetal development in mammals. Amino Acids. 2013;45(2):241-56.

18. Kwon H, Ford SP, Bazer FW, Spencer TE, Nathanielsz PW, Nijland MJ, et al. Maternal undernutrition reduces concentrations of amino acids and polyamines in ovine fetal plasma and placental fluids. Biol Reprod. 2004;71(3):901-8. 
19. Wu GY, Bazer FW, Datta S, Johnson GA, Li P, Satterfield MC, et al. Proline metabolism in the conceptus: implications for fetal growth and development. Amino Acids. 2008;35(4):691-702.

20. Faure M, Mettraux C, Moennoz D, Godin JP, Vuichoud J, Rochat F, et al. Specific amino acids increase mucin synthesis and microbiota in dextran sulfate sodium-treated rats. J Nutr. 2006;136(6):1558-64

21. Koren O, Goodrich JK, Cullender TC, Spor A, Laitinen K, Backhed HK, et al. Host remodeling of the gut microbiome and metabolic changes during pregnancy. Cell. 2012;150(3):470-80.

22. Chalvon-Demersay T, Blachier F, Tomé D, Blais A. Animal models for the study of the relationships between diet and obesity: a focus on dietary protein and estrogen deficiency. Front Nutr. 2017:4(5). https://doi.org/10. 3389/fnut.2017.00005. eCollection 2017

23. Kong XF, Ji YJ, Li HW, Zhu Q, Blachier F, Geng MM, et al. Colonic luminal microbiota and bacterial metabolite composition in pregnant Huanjiang mini-pigs: effects of food composition at different times of pregnancy. Sci Rep. 2016;6(37224). https://doi.org/10.1038/srep37224.

24. Yin YL, Yao K, Liu ZJ, Gong M, Ruan Z, Deng D, et al. Supplementing L-leucine to a low-protein diet increases tissue protein synthesis in weanling pigs. Amino Acids. 2010;39(5):1477-86.

25. Kong XF, Wu GY, Liao YP, Hou ZP, Liu HJ, Yin FG, et al. Effects of Chinese herbal ultra-fine powder as a dietary additive on growth performance serum metabolites and intestinal health in early-weaned piglets. Livest Sci. 2007; 108(1-3):272-5

26. Liu YY, Li FN, Kong XF, Tan BE, Li YH, Duan YH, et al. Signaling pathways related to protein synthesis and amino acid concentration in pig skeletal muscles depend on the dietary protein level, genotype and developmental stages. PLoS One. 2015;10(9):e0138277.

27. Fanca-Berthon P, Hoebler C, Mouzet E, David A, Michel C. Intrauterine growth restriction not only modifies the cecocolonic microbiota in neonatal rats but also affects its activity in young adult rats. J Pediatr Gastroenterol Nutr. 2010;51(4):402-13.

28. Jost T, Lacroix C, Braegger C, Chassard C. Stability of the maternal gut microbiota during late pregnancy and early lactation. Curr Microbiol. 2014;68(4):419-27.

29. Zhou XL, Kong XF, Lian GQ, Blachier F, Geng MM, Yin YL. Dietary supplementation with soybean oligosaccharides increases short-chain fatty acids but decreases protein-derived catabolites in the intestinal luminal content of weaned Huanjiang mini-piglets. Nutr Res. 2014;34(9):780-8.

30. Xu LW, Geng MM, Zhang LP, Yuan HZ, Kong XF, Wang JR. Determination of bioamines in colonic contents of piglets by pre-column. Acta Nutrimenta Sinica. 2014:6(36):78-83.

31. Ma J, Prince AL, Bader D, Hu M, Ganu R, Baquero K, et al. High-fat maternal diet during pregnancy persistently alters the offspring microbiome in a primate model. Nat Commun. 2014;5(3889). https://doi.org/10.1038/ncomms4889.

32. Zhang T, Zha W, Tang ZL, Kong XF. Efects of dietary proline on body composition in pregnant Huanjiang mini-pigs. Chin J Anim Nutr. 2017;29(2):556-61

33. Newell-Fugate AE, Taibl JN, Clark SG, Alloosh M, Sturek M, Krisher RL. Effects of diet-induced obesity on metabolic parameter and reproductive function in female Ossabaw minipigs. Comp Med. 2014;64(1):44-9.

34. Ferrazzi E, Sears B, editors. Metabolic syndrome and complications of pregnancy: the potential preventive role of nutrition. AG, Swizerland: Springer International Publishing; 2015.

35. Luo $Y$, Qu H, Wang $H$, Wei $H$, Wu J, Duan $Y$, et al. Plasma periostin levels are increased in Chinese subjects with obesity and type 2 diabetes and are positively correlated with glucose and lipid parameters. Mediat Inflamm. 2016:6423637.

36. Mandal S, Godfrey KM, McDonald D, Treuren WV, Bjørnholt JV, Midtvedt T, et al. Fat and vitamin intakes during pregnancy have stronger relations with a pro-inflammatory maternal microbiota than does carbohydrate intake. Microbiome. 2016:4(1):55

37. Santacruz A, Collado MC, Garcia-Valdes L, Segura MT, Martin-Lagos JA, Anjos T, et al. Gut microbiota composition is associated with body weight, weight gain and biochemical parameters in pregnant women. Brit J Nutr. 2010;104(1):83-92.

38. Turnbaugh PJ, Ley RE, Mahowald MA, Magrini V, Mardis ER, Gordon Jl. An obesity-associated gut microbiome with increased capacity for energy harvest. Nature. 2006:444(7122):1027-31

39. Donohoe DR, Garge N, Zhang XX, Sun W, O'Connell TM, Bunger MK, et al. The microbiome and butyrate regulate energy metabolism and autophagy in the mammalian colon. Cell Metab. 2011;13(5):517-26.
40. Perry RJ, Peng L, Barry NA, Cline GW, Zhang D, Cardone RL, et al. Acetate mediates a microbiome-brain-beta-cell axis to promote metabolic syndrome. Nature. 2016;534(7606):213-7.

41. Ríos-Covián D, Ruas-Madiedo P, Margolles A, Gueimonde M, de Los ReyesGavilán CG, Salazar N. Intestinal short chain fatty acids and their link with diet and human health. Front Microbiol. 2016;7:185.

42. Louis P, Hold GL, Flint HJ. The gut microbiota, bacterial metabolites and colorectal cancer. Nat Rev Microbiol. 2014;12(10):661-72.

43. Blachier F, Mariotti F, Huneau JF, Tomé D. Effects of amino acid-derived luminal metabolites on the colonic epithelium and physiopathological consequences. Amino Acids. 2007:33(4):547-62.

44. Wang L, Conlon MA, Christophersen CT, Sorich MJ, Angley MT. Gastrointestinal microbiota and metabolite biomarkers in children with autism spectrum disorders. Biomark Med. 2014;8(3):331-44.

45. Burcelin R. Regulation of metabolism: a cross talk between gut microbiota and its human host. Physiology. 2012;27(5):300-7.

46. Remely M, Hippe B, Geretschlaeger I, Stegmayer S, Hoefinger I, Haslberger A. Increased gut microbiota diversity and abundance of Faecalibacterium prausnitzii and Akkermansia after fasting: a pilot study. Wien Klin Wochenschr. 2015;127(9-10):394-8.

47. Stenman LK, Burcelin R, Lahtinen S. Establishing a causal link between gut microbes, body weight gain and glucose metabolism in humans-towards treatment with probiotics. Benef Microbes. 2015;7(1):11-22

48. Yao P, Cui M, Wang H, Gao H, Wang L, Yang T, et al. Quantitative analysis of intestinal flora of Uygur and Han ethnic Chinese patients with ulcerative colitis. Gastroenterol Res Pract. 2016:9186232.

49. Flint HJ, Bayer EA, Rincon MT, Lamed R, White BA. Polysaccharide utilization by gut bacteria: potential for new insights from genomic analysis. Nat Rev Microbiol. 2008;6(2):121-31.

50. Kelly CJ, Zheng L, Campbell EL, Saeedi B, Scholz CC, Bayless AJ, et al. Crosstalk between microbiota-derived short-chain fatty acids and intestinal epithelial HIF augments tissue barrier function. Cell Host Microbe. 2015;17(5):662-71.

51. Vidal-Lletjós S, Beaumont M, Tomé D, Benamouzig R, Blachier F, Lan A. Dietary protein and amino acid supplementation in inflammatory bowel disease course: what impact on the colonic mucosa? Nutrients. 2017;9(3):310.

52. Dai ZL, Wu ZL, Hang SO Zhu WY, Wu GY. Amino acid metabolism in intestinal bacteria and its potential implications for mammalian reproduction. Mol Hum Reprod. 2015:21(5):389-409.

53. Davila AM, Blachier F, Gotteland M, Andriamihaja M, Benetti PH, Sanz Y, et al. Intestinal luminal nitrogen metabolism: role of the gut microbiota and consequences for the host. Pharmacol Res. 2013;68(1):95-107.

54. Wu GD, Chen J, Hoffmann C, Bittinger K, Chen YY, Keilbaugh SA, et al. Linking long-term dietary patterns with gut microbial enterotypes. Science. 2011;334(6052):105-8.

55. Ren W, Wu M, Luo W, Huang R, Yin Y, Li Y, et al. Dietary supplementation with proline confers a positive effect in both porcine circovirus-infected pregnant and non-pregnant mice. Br J Nutr. 2013;110(8):1492-9.

56. Shah P, Swlatlo E. A multifaceted role for polyamines in bacterial pathogens. Mole Microbiol. 2008:68(1):4-16.

57. Wallace HM, Fraser AV, Hughes A. A perspective of polyamine metabolism. Biochem J. 2003;376:1-14.

58. Goytia M, Shafer WM. Polyamines can increase resistance of Neisseria gonorrhoeae to mediators of the innate human host defense. Infect Immun. 2010;78(7):3187-95.

59. Jelsbak L, Thomsen LE, Wallrodt I, Jensen PR, Olsen JE. Polyamines are required for virulence in Salmonella enterica serovar typhimurium. PLoS One. 2012;7(4):e36149.

60. Nelson TM, Borgogna JL, Brotman RM, Ravel J, Walk ST, Yeoman CJ. Vaginal biogenic amines: biomarkers of bacterial vaginosis or precursors to vaginal dysbiosis? Front Physiol. 2015;6(253). https://doi.org/10.3389/fphys.2015. 00253. eCollection 2015.

61. Watson N, Dunyak DS, Rosey EL, Slonczewski JL, Olson ER. Identification of elements involved in transcriptional regulation of the Escherichia-Coli-cad operon by external pH. J Bacteriol. 1992;174(2):530-40.

62. Armougom F, Henry M, Vialettes B, Raccah D, Raoult D. Monitoring bacterial community of human gut microbiota reveals an increase in Lactobacillus in obese patients and methanogens in anorexic patients. PLOS One. 2009:4(9):e7125.

63. Fernando SC, Purvis HT, Najar FZ, Sukharnikov LO, Krehbiel CR, Nagaraja TG, et al. Rumen microbial population dynamics during adaptation to a highgrain diet. Appl Environ Microbiol. 2010;76(22):7482-90. 
64. Matsuki T, Watanabe K, Fujimoto J, Miyamoto Y, Takada T, Matsumoto K, et al. Development of 165 rRNA-gene-targeted group-specific primers for the detection and identification of predominant bacteria in human feces. Appl Environ Microbiol. 2002;68(11):5445-51.

65. Bartosch S, Fite A, Macfarlane GT, McMurdo ME. Characterization of bacterial communities in feces from healthy elderly volunteers and hospitalized elderly patients by using real-time PCR and effects of antibiotic treatment on the fecal microbiota. Appl Environ Microbiol. 2004;70(6):3575-81.

66. Matsuki T, Watanabe K, Fujimoto J, Takada T, Tanaka R. Use of $16 \mathrm{~S}$ rRNA gene-targeted group-specific primers for real-time PCR analysis of predominant bacteria in human feces. Appl Environ Microbiol. 2004;70(12):7220-8.

67. Wang RF, Cao WW, Cerniglia CE. PCR detection and quantitation of predominant anaerobic bacteria in human and animal fecal samples. Appl Environ Microbiol. 1996:62(4):1242-7.

68. Ramirez-Farias C, Slezak K, Fuller Z, Duncan A, Holtrop G, Louis P. Effect of inulin on the human gut microbiota: stimulation of Bifidobacterium adolescentis and Faecalibacterium prausnitzii. Brit J Nutr. 2009;101(4):541-50.

69. Armougom F, Raoult D. Use of pyrosequencing and DNA barcodes to monitor variations in Firmicutes and Bacteroidetes communities in the gut microbiota of obese humans. BMC Genomics. 2008;9:576.

70. Rinttila T, Kassinen A, Malinen E, Krogius L, Palva A. Development of an extensive set of $16 \mathrm{~S}$ rDNA-targeted primers for quantification of pathogenic and indigenous bacteria in faecal samples by real-time PCR. J Appl Microbiol. 2004;97(6):1166-77.

71. Shannon KE, Lee DY, Trevors JT, Beaudette LA. Application of real-time quantitative PCR for the detection of selected bacterial pathogens during municipal wastewater treatment. Sci Total Environ. 2007;382(1):121-9.

72. Menard JP, Fenollar F, Henry M, Bretelle F, Raoult D. Molecular quantification of gardnerella vaginalis and atopobium vaginae loads to predict bacterial vaginosis. Clin Infect Dis. 2008:47(1):33-43.

73. Ouwerkerk D, Klieve AV, Forster RJ. Enumeration of Megasphaera elsdenii in rumen contents by real-time taq nuclease assay. J Appl Microb. 2002;92(4):753-8.

74. Schwartz T, Volkmann H, Kirchen S, Kohnen W, Schön-Hölz K, Jansen B, et al. Real-time PCR detection of Pseudomonas aeruginosa in clinical and municipal wastewater and genotyping of the ciprofloxacin-resistant isolates. FEMS Microbiol Ecol. 2006;57(1):158-67.

75. Yadav JS, Khan IU, Fakhari F, Soellner MB. DNA-based methodologies for rapid detection, quantification, and species- or strain-level identification of respiratory pathogens (mycobacteria and pseudomonads) in metalworking fluids. Appl Occup Environ Hyg. 2003;18(11):966-75.

76. Larsen N, Vogensen FK, van den Berg FW, Nielsen DS, Andreasen AS, Pedersen BK, et al. Gut microbiota in human adults with type 2 diabetes differs from non-diabetic adults. PLoS One. 2010;5(2):e9085.

77. Tajima K, Aminov Rl, Nagamine T, Matsui H, Nakamura M, Benno Y. Dietdependent shifts in the bacterial population of the rumen revealed with real-time PCR. Appl Environ Microbiol. 2001;67(6):2766-74.

\section{Submit your next manuscript to BioMed Central and we will help you at every step:}

- We accept pre-submission inquiries

- Our selector tool helps you to find the most relevant journal

- We provide round the clock customer support

- Convenient online submission

- Thorough peer review

- Inclusion in PubMed and all major indexing services

- Maximum visibility for your research

Submit your manuscript at www.biomedcentral.com/submit 